\title{
ANALYSIS OF THE POTENTIAL OF UNIDIRECTIONAL AND BIDIRECTIONAL PRICE CONTROLLED CHARGING STRATEGIES
}

\author{
Georg STOECKL \\ Institute of Power Transmission Systems \\ Technische Universität München, Germany \\ georg.stoeckl@tum.de
}

\author{
Rolf WITZMANN \\ Institute of Power Transmission Systems \\ Technische Universität München, Germany \\ rolf.witzmann@tum.de
}

\begin{abstract}
The increasing share of electric vehicles (EVs) in the coming years will lead to an additional load. Most vehicles come home during the afternoon and evening. Charging them directly after their arrival (plug and charge strategy) would lead to an increase of the consumption peak in the evening. But EVs are usually connected to the grid for longer than they need to charge their batteries. This enables them to be charged at times of low power demand and low electricity prices (unidirectional price controlled charging strategy) and to thereby even out the power consumption. Furthermore, it is possible to feed in power when the electricity price is high (bidirectional price controlled charging strategy). In this scenario, EVs would serve as a storage device. This paper introduces a simulation model for the plug and charge, the unidirectional, and the bidirectional price controlled charging strategies. These strategies are then compared to each other regarding profitability and technical constraints.
\end{abstract}

\section{INTRODUCTION}

EVs are an additional load and will increase the loading of the grid in the future. On the other hand they can be used for ancillary services. Charging EVs when the electricity price is low would be one possibility. Using fluctuations of the electricity price to feed electricity back into the grid (vehicle-to-grid) would be another.

\section{ELECTRICITY PRICE}

The intraday market of the European Power Exchange (EPEX SPOT SE) allows customers to trade 15-minute periods or 1-hour periods starting at $3 \mathrm{pm}$ for the following day until 45 minutes before delivery begins. The German intraday price of the EPEX SPOT SE of the year 2011 was used as the power generation price in the following studies. [1] Fees and taxes were added to get the final price paid by the consumer, which was on average $0.2523 € / \mathrm{kWh}[2]$ in Germany in 2011.

The effect of higher price fluctuations was evaluated in this paper by increasing the fluctuations while keeping the average constant. The price variation factor $\mathrm{k}$ is the quotient of the variance of the modified price divided by the variance of the original price.

\section{LOW-VOLTAGE NETWORKS}

General statements cannot be gained by analyzing just one low-voltage network because each network is unique in its design and dimensions. Therefore, the reference networks from [3] where used in this paper. These reference networks were developed by statistically analyzing 87 low-voltage networks in Bavaria, Germany. The results of this analysis are typical low-voltage networks for rural areas, villages and suburbs.

The households and farms in these networks were modeled using statistically generated load profiles. These load profiles were gained by using statistics concerning the user behavior of different types of house hold loads (e.g. lights, refrigerators and computers). For more information on these load profiles please refer to [4].

\section{STATISTICAL TRAFFIC MODEL}

In order to choose the best time when to charge an EV, the charging system must know the time of its departure. It is therefore necessary that its owner enters the time of the next departure into the charging system. The time of arrival and departure differs from day to day and from vehicle to vehicle. They are therefore determined with the help of a statistical traffic model, which also calculates the travelled distance.

At first it is determined whether the $\mathrm{EV}$ is driven on a given day or not. In Germany this is the case for $74 \%$ of cars on average [5]. The travelled distance is then determined with the help of the distribution of annual car mileage taken from [6].

Reference [7] evaluates the parking space demand in different areas in Germany. With the help of the time of the parking space access and departure times from this study, the conditional cumulative distribution functions (CCDFs) of incoming and outgoing cars were derived [8]. CCDFs have to be used because the probability functions are dependant. With these CCDFs the arrival and departure times of each vehicle on each day is determined.

\section{PLUG AND CHARGE STRATEGY (PCS)}

In the plug and charge strategy EVs are charged as soon as they return home with nominal power until their batteries are full. The nominal power used in this paper is $11 \mathrm{~kW}$ 
(three-phase charging with $400 \mathrm{~V}$ and $16 \mathrm{~A}$ ). The advantage of this charging strategy is its simplicity. There is no communication and no sophisticated controlling device needed. Figure 1 shows the average number of EVs that are being charged in a suburban network with 146 electric vehicles as well as the average price. Most vehicles come home during the evening hours. This leads to a load peak between 16:00 and 22:00, when the electricity price and the power consumption of the households are high.

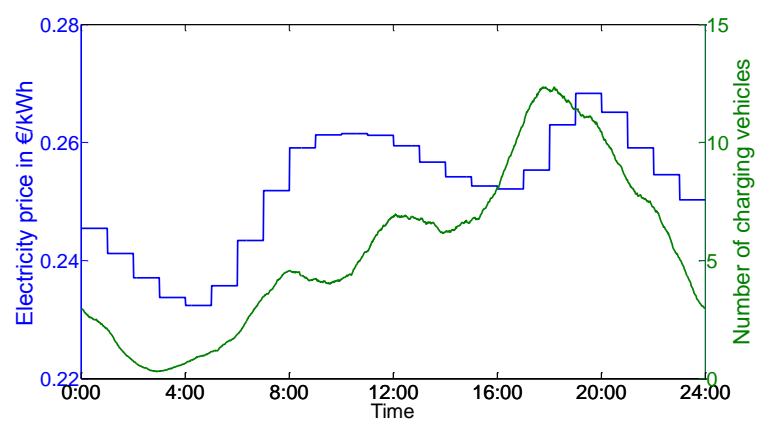

Figure 1: Average electricity price and number of charging vehicles of a one year simulation with $146 \mathrm{EV}$ s for the PCS

\section{UNIDIRECTIONAL PRICE CONTROLLED CHARGING STRATEGY (UCS)}

The goal of this charging strategy is to minimize charging costs. With the help of the EPEX SPOT price, the most economic time frame for each vehicle is determined. Most vehicles are charged between 2:00 and 7:00 in the morning, as shown in Figure 2. During the peak at 4:00 around $34 \%$ of the EVs are charged.

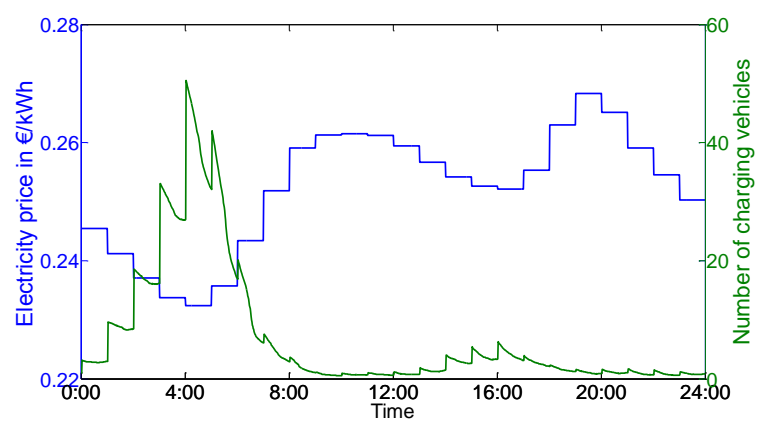

Figure 2: Average electricity price and number of charging vehicles of a one year simulation with $146 \mathrm{EV}$ s for the UCS

\section{Power limitation}

The price controlled charging strategy leads to a high simultaneity factor which in consequence can cause overloading. This has to be avoided by limiting the maximum charging power of each EV. A reduction of the charging power leads to an extension of the charging time. This could cause some EVs to not be fully charged until their next departure. To prevent this, all EVs have to send a signal of their minimal charging power $P_{\min }$, necessary to fully charge them until their next departure, to a centralized control unit. The centralized control unit then determines the charging power of each EV which has to be greater than $P_{\text {min }}$.

\section{BIDIRECTIONAL PRICE CONTROLLED CHARGING STRATEGY (BCS)}

The bidirectional charging strategy uses high price fluctuations to feed energy back into the grid and thus gain profit. This is done by charging the EVs when the electricity price is low and feeding energy into the grid when the electricity price is high. At first, the maximum electricity price $p_{\max }$ during the time the $E V$ is plugged in is determined. The minimum price before and after the maximum price $\left(p_{\min 1 \text { and }} p_{\min 2}\right)$ is then determined. The following condition has to be fulfilled in order to feed electricity into the grid:

$$
\left(\frac{p_{\max }}{p_{\min 1}}>q\right) \&\left(\frac{p_{\max }}{p_{\min 2}}>q\right)
$$

The parameter $q$ is the price quotient for which feed-in is profitable. It depends on the fluctuation of the electricity price, the battery price and the efficiency of the charging process.

The additional charging cycles of the bidirectional price controlled charging strategy lead to excess aging and a shortened lifetime of the battery. The losses during the charging process also have to be considered. These two effects have a big influence on the economics. The difficulty of this charging strategy is to determine the price where it is profitable to feed into the grid.

\section{Charging losses}

The revenue $\mathrm{R}_{\text {feed }}$ of feeding in the energy $E_{\text {feed }}$ at the price $\mathrm{p}_{\text {feed }}$ with the charging efficiency $\eta$ amounts to

$$
R_{\text {feed }}=E_{\text {feed }} \cdot \eta \cdot p_{\text {feed }} \text {. }
$$

The battery has to be charged by $E_{\mathrm{ch}}=E_{\text {feed }}$ to have the same amount of energy in the battery as before the feed-in. Therefore the energy $E_{\mathrm{ch}} / \eta$ has to be taken out of the grid. This leads to charging costs of

$$
C_{c h}=\frac{E_{c h}}{\eta} p_{c h} \text {. }
$$

Where:

$p_{\text {ch }}$ : price during the charging process

In order for the bidirectional charging to be profitable (neglecting aging due to additional charging cycles), the following conditions have to be fulfilled

$$
\begin{aligned}
& E_{\text {feed }} \cdot \eta \cdot p_{\text {feed }}>\frac{E_{c h}}{\eta} \cdot p_{c h} . \\
& \frac{p_{\text {feed }}}{p_{c h}}>\frac{1}{\eta^{2}} .
\end{aligned}
$$

With $E_{\text {ch }}=E_{\text {feed }}$ 
This means that for a charging efficiency of $83.66 \%$ [9] the price during discharging must be at least 1.43 times as high as during charging.

\section{Battery Aging}

The simplified battery degradation model which was developed in reference [10] is used in the following. This model calculates the estimated cycle life $N_{\text {life }}$ of Li-Ion batteries in dependency of the depth of discharge DOD by using (6).

$$
N_{\text {life }}=1331 \cdot D O D^{-1.825} .
$$

This means that a Li-Ion battery has a lifetime of 2000 cycles for a DOD of $80 \%$ and 800000 cycles for a DOD of $3 \%$. The aging costs $C_{\text {age }}$ for one discharge can be determined with the help of the specific battery investment costs $p_{\text {battery }}$ by using (7).

$$
C_{\text {age }}=\frac{p_{\text {battery }}}{N_{\text {life }}(D O D) \cdot D O D} .
$$

In this paper, specific battery investment costs of $350 € / \mathrm{kWh}[10]$ were assumed. In order to assess the future potential of vehicle-to-grid, investment costs of $120 € / \mathrm{kWh}$ [11] were used. The aging costs increase with the DOD. Thus the maximum DOD has to be limited depending on the price fluctuations. The aging costs for a full cycle for $p_{\text {battery }}=350 € / \mathrm{kWh}$ are $0.26 € / \mathrm{kWh}$, see Figure 3 . These costs are very high compared to the average variation of the electricity price in 2011, which was $0.036 € / \mathrm{kWh}$. Therefore, it does not make sense to fully discharge the battery.

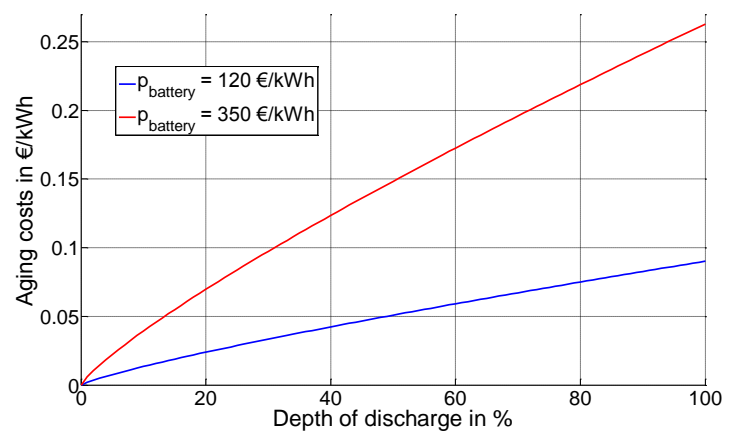

Figure 3: Aging costs as a function of the DOD

\section{COMPARISON OF CHARGING STRATEGIES}

The peak of the charging power of the PCS and the households are approximately at the same time. The simulations show that the typical Bavarian low voltage grids are dimensioned to handle such big loads. For highly loaded grids, however, this can lead to overloading. The peaks of the two price controlled charging strategies are during the night, when the consumption of the households is very low. The combined peak of the EVs and the households, as shown in Figure 4, is much higher for the price controlled charging strategies than for the PCS due to the high simultaneity factor. The transformer rating however is not exceeded in case of the UCS and BCS because of the power limitation. In grids with transformers with a low load to rated power ratio the UCS and BCS can lead to problems. It could happen that overloading can only be avoided if the charging power is reduced so far that some EVs are not fully charged until the next departure. In the investigated reference grids this was not the case.

Globally the controlled charging strategies can even out the power consumption. For a high global amount of EVs, dynamic pricing is necessary. If in this case too many EVs are charged simultaneously, the price would go up and some EVs would stop charging.

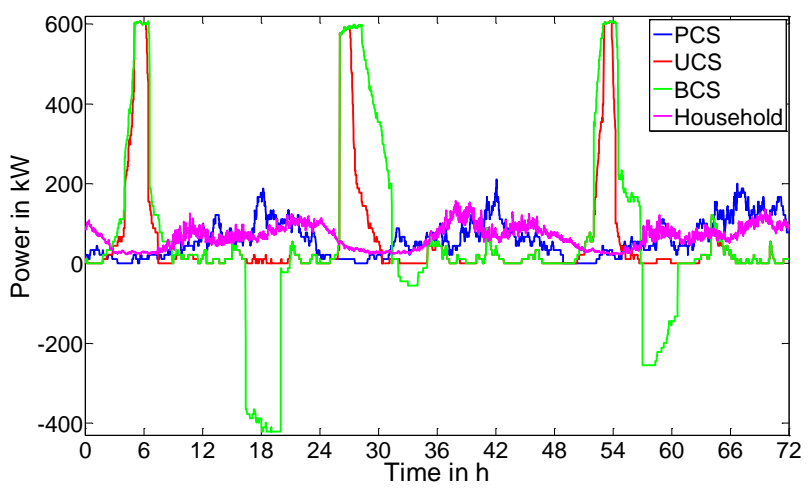

Figure 4: Charging power and household consumption with one EV per household (rated transformer power $630 \mathrm{kVA}$ )

\section{Price Comparison PCS-UCS}

The PCS leads to a lot of charging processes in the evening, when prices are high (see Figure 1). Its costs are therefore the highest. The annual charging costs for the UCS are about $86 €$ or $9 \%$ less than for the UCS with the price of 2011. These savings increase to $172 €$ for $k=2$ and to $256 €$ for $k=3$. Compared to the single price tariff saving between $35 €(k=1)$ and $166 €(k=3)$ can be achieved.

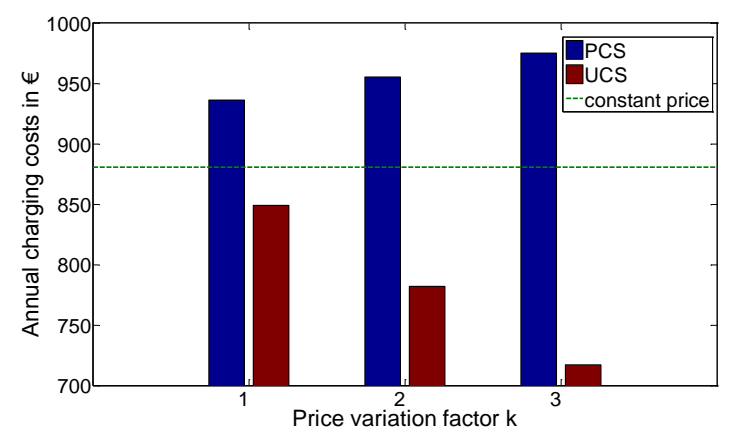

Figure 5: Cost comparison between PCS and UCS

\section{Price Comparison UCS-BCS}

The price fluctuation must be greater than $1 / \eta^{2}$ to make up for the losses and even higher to additionally cover the 
battery aging. The BCS with the standard parameters ( $p_{\text {battery }}=350 € / \mathrm{kWh}, k=1, \eta=0.8366$ ) is not profitable, because such high price fluctuations are very rare. Figure 6 shows the effect of the parameters on the costs. For $k=1$ the price fluctuations are too small and for $\eta=0.8366$ the losses are too high to make profit. In order to save a significant amount of money compared to the UCS, the efficiency as well as the price fluctuation factor need to increase and the prices for batteries must decrease. For $p_{\text {battery }}=120 € / \mathrm{kWh}, k=3, \eta=0.95$ the annual charging costs are $122 €$ less but the additional annual aging costs are $55 €$. This adds up to an annual saving of $67 €$. The annual energy feed into the grid is $1282 \mathrm{kWh}$, which is $42 \%$ of the average annual energy consumption of an EV. Even in this highly optimistic scenario, it is doubtful if EV owners are willing to give the control over their battery to the grid operator for $67 €$, considering the uncertainty of the exact battery aging costs.

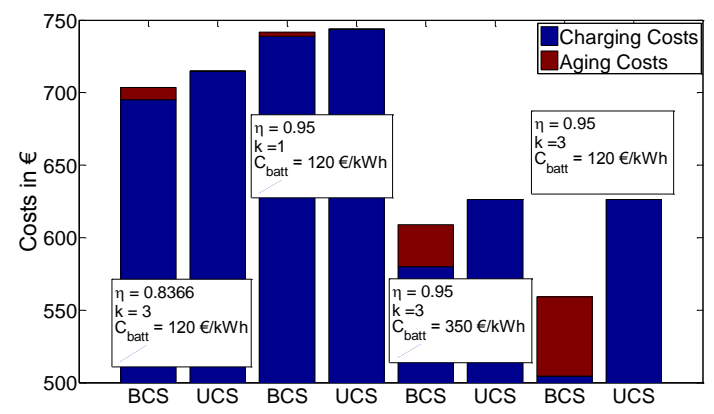

Figure 6: Cost comparison between UCS and BCS

\section{CONCLUSION}

The price controlled charging strategies lead to an increase in the local consumption peak. With the help of power limitation, this peak does not exceed the transformer rating. The UCS could be the first step towards controlled charging strategies. Its costs are significantly less than the costs of the PCS. Increasing price fluctuations work in its favor.

The BCS is currently not profitable. In order to make a significant profit, the price fluctuation as well as the efficiency has to increase and the battery prices have to decrease. Even then, special charging rates are necessary to make bidirectional charging economically interesting to the consumers.

\section{REFERENCES}

[1] EPEX SPOT, "Products Intraday", Internet: http://www.epexspot.com/en/productinfo/Intraday/germany [12.12.2012]

[2] BDEW Bundesverband der Energie- und Wasserwirtschaft e.V, "BDEW-Strompreisanalyse Oktober 2012”, Internet:
http://bdew.de/internet.nsf/id/123176ABDD9ECE5DC 1257AA20040E368/\$file/121026_BDEW_Strompreis analyse_Oktober\%202012_Update_26.10.2012.pdf, 26.10.2012, [12.12.2012]

[3] G. Kerber, „Aufnahmefähigkeit von Niederspannungsverteilnetzen für die Einspeisung aus Photovoltaikanlagen”, Der Andere Verlag, Uelvesbüll, Germany 2011

[4] P. Esslinger, R. Witzmann, „Entwicklung und Verifikation eines stochastischen Verbraucherlastmodells für Haushalte" 12. Symposium Energieinnovation 2012, February 2012, Graz/Austria

[5] H. Hautzinger, B. Tassaux, R. Hamacher, "Elektroauto und Mobilität-Das Einsatzpotential von Elektroautos", IVT Heilbronn, Germany 1992

[6] German Federal Ministry of Transport, Building and Urban Development, "Mobilität in Deutschland 2008", Germany 2008

[7] Bundesanstalt für Straßenwesen, "Kennlinien der Parkraumnachfrage", Wirtschaftsverlag NW, Bremerhaven, Germany, 2000

[8] G. Stöckl, R. Witzmann, „Charging Strategies for Electric Vehicles in Low Voltage Grids with a High Amount of Distributed Renewable Energies“, IEEE International Conference on Power Engineering, Energy and Electrical Drives 2013, Istanbul, Manuscript submitted for publication

[9] M. Winter, "Introduction into Li-Ion Battery Materials", Advanced Battery Technologies for Automobiles and Their Electric Power Grid Integration, Essen, January 2009

[10] J. Link, M. Büttner, D. Dallinger, J. Richter, „Optimisation Algorithms for the Charge Dispatch of Plug-in Vehicles based on Variable Tariffs", Working Papers Sustainability and Innovation No. 32010 , Fraunhofer Institute for Systems and Innovation Research (ISI)

[11] R. Hensley, J. Newman, M. Rogers, "Battery technology charges ahead", McKinseyQuaterly, July 2012 